\title{
Family-Focused Treatment for Adolescents With Bipolar Disorder:
}

\author{
Results of a 2-Year Randomized Trial \\ David J. Miklowitz, PhD, David A. Axelson, MD, Boris Birmaher, MD, Elizabeth L. George, \\ PhD, Dawn O. Taylor, PhD, Christopher D. Schneck, MD, Carol A. Beresford, MD, L. Miriam \\ Dickinson, PhD, W. Edward Craighead, PhD, and David A. Brent, MD \\ Department of Psychology, University of Colorado, Boulder (Drs Miklowitz, George, Taylor, and \\ Craighead); Western Psychiatric Institute and Clinic, University of Pittsburgh School of Medicine, \\ Pittsburgh, Pennsylvania (Drs Axelson, Birmaher, and Brent); and Department of Psychiatry, \\ University of Colorado Health Sciences Center, Denver (Drs Miklowitz, Schneck, Beresford, and \\ Dickinson).
}

\begin{abstract}
Context-Family interventions have been found to hasten episode recovery and delay recurrences among adults with bipolar disorder.
\end{abstract}

Objective-To examine the benefits of family-focused treatment for adolescents (FFT-A) and pharmacotherapy in the 2-year course of adolescent bipolar disorder.

\begin{abstract}
Design-Two-site outpatient randomized controlled trial with 2-year follow-up.
Patients-A referred sample of 58 adolescents (mean [SD] age, 14.5[1.6] years) with bipolar I $(\mathrm{n}=38)$, II $(\mathrm{n}=6)$, or not otherwise specified disorder $(\mathrm{n}=14)$ with a mood episode in the prior 3 months.
\end{abstract}

Interventions-Patients were randomly assigned to FFT-A and protocol pharmacotherapy $(n=30)$ or enhanced care (EC) and protocol pharmacotherapy $(n=28)$. The FFT-A consisted of 21 sessions in 9 months of psychoeducation, communication training, and problem-solving skills training. The EC consisted of 3 family sessions focused on relapse prevention.

Main Outcome Measures-Independent "blind" evaluators assessed patients every 3 to 6 months for 2 years. Outcomes included time to recovery from the index episode, time to recurrence, weeks in episode or remission, and mood symptom severity scores.

Results-Analyses were by intent to treat. Rates of 2-year study completion did not differ across the FFT-A (60.0\%) and EC conditions (64.3\%). Although there were no group differences in rates

\footnotetext{
(C) 2008 American Medical Association. All rights reserved.

Correspondence: David J. Miklowitz, PhD, Department of Psychology, Muenzinger Bldg, University of Colorado, Boulder, CO 80309-0345 (miklowitz@colorado.edu)..

Author Contributions: Dr Miklowitz verifies that he had full access to all of the data in the study and takes responsibility for the integrity of the data and the accuracy of the data analysis. Dr Dickinson was the project statistician.

Additional Contributions: Adrine Biuckians, MA, Tina Goldstein, PhD, Eunice Kim, PhD, Kimberley Mullen, MA, Amy Schlonski, LCSW, and Tim Winbush, LCSW, served as study therapists; Susan Wassick, RN, Amy Mechels, MA, Chad Morris, PhD, Victoria Cosgrove, MA, and Laura Wagenknecht, MA, served as independent evaluators; and Mary Beth Hickey served as the study's data manager.

Financial Disclosure: Dr Miklowitz reported receiving funding from the National Institute of Mental Health (NIMH), the National Association for Research on Schizophrenia and Depression, the Robert Sutherland Foundation, and the Danny Alberts Foundation, and book royalties from Guilford Press and John Wiley and Sons. Dr Birmaher reported receiving honoraria from Solvay Pharmacueticals and Abcomm, Inc, and book royalties from Random House, Inc. Dr Craighead reported receiving honoraria from Forest Laboratories, Eli Lilly Co, and Novadel, and book royalties from John Wiley and Sons.

Previous Presentation: The results were presented in part at the annual meeting of the American Association of Child and Adolescent Psychiatry; October 24, 2007; Boston, Massachusetts.
} 
of recovery from the index episode, patients in FFT-A recovered from their baseline depressive symptoms faster than patients in EC (hazard ratio, 1.85 ; 95\% confidence interval, 1.04-3.29; $P=.04$ ). The groups did not differ in time to recurrence of depression or mania, but patients in FFT-A spent fewer weeks in depressive episodes and had a more favorable trajectory of depression symptoms for 2 years.

Conclusions-Family-focused therapy is effective in combination with pharmacotherapy in stabilizing bipolar depressive symptoms among adolescents. To establish full recovery, FFT-A may need to be supplemented with systematic care interventions effective for mania symptoms.

Trial Registration-clinicaltrials.gov Identifier NCT00571402.

вETWEEN $50 \%$ AND $66 \%$ оF вipolar patients have illness onset before age 18, and between $13 \%$ and $28 \%$ before age $13 .{ }^{1,2}$ Early onset of illness is associated with an unremitting course of illness, frequent switches of polarity, mixed episodes, psychosis, a high risk of suicide, and poor functioning or quality of life. ${ }^{3-10}$

The past decade has witnessed a remarkable increase in diagnoses of bipolar disorder in children and adolescents and, correspondingly, drug trials for patients with early-onset disorder. ${ }^{11,12}$ There has been comparatively little controlled examination of psychotherapy for pediatric patients. Among 35 families with bipolar children (aged 8-11 years), multifamily psychoeducation groups promoted better social support and access to health care than a waitlist control. ${ }^{13}$ Two open trials found improvements in mood symptoms for 1 to 3 years among bipolar children and adolescents who received pharmacotherapy, family skills training, and individual therapy. ${ }^{14,15}$

In contrast, there has been a considerable increase in the number of randomized trials examining adjunctive psychotherapies for adult bipolar patients. ${ }^{16}$ Notably, adults given pharmacotherapy and family-focused therapy (FFT), a 9-month, 21-session intervention consisting of psychoeducation for the family regarding bipolar disorder, communication training, and problem-solving skills training had longer healthy intervals prior to recurrences than patients receiving medication and brief psychoeducation in one trial ${ }^{17}$ or medication and equally intensive individual psychoeducation in another trial. ${ }^{18}$ The 15 -site Systematic Treatment Enhancement Program for Bipolar Disorder found that medication and up to 30 sessions of FFT, cognitive-behavioral therapy, or interpersonal and social rhythm therapy were more effective than medication and minimal psychoeducation in speeding recovery from bipolar depression, maintaining wellness, and enhancing functioning and quality of life for 1 year. ${ }^{19}$, 20

In a treatment development trial ${ }^{21}(\mathrm{~N}=20)$, we adapted the FFT model to adolescents (FFTA), and showed that it was feasible, acceptable, and associated with improvements in mood symptoms for 2 years. In this article, we report results from a 2-site randomized trial of FFT$\mathrm{A}$ and medication in comparison with enhanced care (EC; ie, 3 sessions of family education) and medication for bipolar adolescents with a recent mood episode. We hypothesized (1) that adolescents undergoing FFT-A would recover more rapidly from episodes of depression or mania and have longer well intervals (without recurrence) than patients in EC, and (2) that treatment with FFT-A would be related to less time in depressed or manic moods and a more favorable trajectory of symptom severity scores for 2 years.

\section{METHODS \\ PARTICIPANTS}

Participants were adolescents with bipolar spectrum disorder with a minimum 1- to 2-week period of illness in the prior 3 months. Adolescents at the University of Colorado site were 
recruited through direct referral by community psychiatrists or the inpatient units of Children's Hospital of Denver. Patients at the University of Pittsburgh School of Medicine site were existing patients or new referrals to the Child and Adolescent Bipolar Services Clinic. Recruitment was from October 2002 to September 2005.

\section{ELIGIBILITY CRITERIA}

Patients met the following criteria: (1) aged between 12 years, 0 months and 17 years, 11 months; (2) a $D S M-I V^{22}$ diagnosis of bipolar I, II, or not otherwise specified (NOS) disorder based on separate Kiddie Schedule for Affective Disorders and Schizophrenia, Present and Lifetime Version (K-SADS-PL ${ }^{23,24}$ ) interviews with the patient and at least 1 parent; (3) concurrent physician diagnosis of bipolar I, II, or NOS based on a separate set of evaluations with the patient and parent (An adolescent was diagnosed with bipolar NOS if he or she had had a distinct period of abnormally elevated, expansive, or irritable mood plus 2 [3 if irritable mood only] DSM-IV symptoms of mania that caused a change in functioning, lasted for at least 1 day, and was present for a total of at least 4 days in the patient's lifetime. This operational definition of bipolar NOS was validated relative to bipolar I and II disorders and found to be associated with considerable psychosocial impairment in the Course and Outcome of Bipolar Youth study. $\left.{ }^{9}, 10\right)$; (4) at least a 1-week episode of manic, mixed, or hypomanic symptoms or a 2-week episode of depressive symptoms within the past 3 months; (5) no severe psychosis lasting 3 or more months; (6) no evidence of mental retardation, neurological illness, or pervasive developmental disorder; (7) no substance or alcohol disorders in the prior 3 months; (8) no eating disorder or medical disorder requiring immediate hospitalization; (9) willingness to proceed with pharmacotherapy from a study psychiatrist; and (10) at least 1 biological parent or stepparent is willing to participate in family treatment.

This study was approved by the institutional review boards of both universities. All parents, adolescent patients, and siblings gave written consent or assent following a thorough explanation of the procedures.

\section{INITIAL DIAGNOSTIC EVALUATION}

Potential participants were screened during an initial telephone contact with the site's project coordinator. Then, trained research staff members (working alone or in pairs) administered the K-SADS-PL to the adolescent and, separately, to at least 1 parent. The interview time frame was lifetime, with current episode ratings based on the most symptomatic 1- to 2-week period in the prior 3 months. The mood sections of the K-SADS-PL were replaced with the K-SADS Depression and Mania Rating Scales (DRS and MRS ${ }^{23-25}$ ), which offer more thorough coverage of current and past symptoms on 1 to 6 scales of severity and impairment. Evaluators also made 1 to 100 ratings of functioning on the Child's Global Assessment Scale $\left(\mathrm{CGAS}^{26}\right)$ for the prior 2 weeks, the most severe past episode, and the highest level in the past year.

Final K-SADS-PL, DRS, MRS, and CGAS scores were based on a consensus between the parents' and adolescents' scores. When discrepancies occurred, the adolescent and parent were consulted conjointly or information from another parent or medical records was obtained. Patients were only included if the study psychiatrist and K-SADS interviewer agreed that a bipolar I, II, or NOS disorder was present.

All K-SADS diagnosticians and independent evaluators had at least a Master of Arts or psychiatric nursing degree. Interrater reliability for K-SADS MRS and DRS scores (51 ratings) was 0.97 and 0.89 (intraclass $r$ ), respectively, and $\kappa=0.70$ for K-SADS-PL comorbid disorders. A midstudy check on rater drift between 10 Colorado raters and 4 Pittsburgh raters yielded $81 \%$ agreement on the K-SADS DRS and $76 \%$ on the K-SADS MRS. 


\section{PHARMACOLOGICAL TREATMENTS}

Once accepted into the trial, a data manager at the University of Pittsburgh randomly assigned patients to pharmacotherapy and FFT-A (50\%) or pharmacotherapy and enhanced care (50\%) using a modification of the Efron biased coin procedure. ${ }^{27}$ Randomizations were stratified by study site (Figure 1).

Patients were treated by study psychiatrists for 2 years according to the best practices known at the time of treatment. Psychiatrists convened monthly teleconferences to review advances in the treatment literature and the diagnosis and management of difficult cases. Medications shown to be effective in bipolar adults and, when data were available, bipolar adolescents (eg, lithium, anticonvulsants, second-generation antipsychotics) formed the basis of pharmacotherapy plans. Adjunctive antidepressants and pharmacotherapy for comorbid attention-deficit hyperactivity disorder or anxiety symptoms were permitted. Treatment guidelines from an expert consensus panel were integrated when they became available. ${ }^{12}$

\section{PSYCHOSOCIAL TREATMENTS}

Family-Focused Therapy for Adolescents-Family-Focused Therapy for Adolescents consisted of 21 50-minute sessions (12 weekly, 6 biweekly, and 3 monthly) for 9 months and included the patient, parents, and available siblings. The goals of the first 7 to 10 sessions (psychoeducation) were to (1) encourage adolescent patients and family members to develop a common understanding of the symptoms, etiology, and course of pediatric bipolar illness and the precipitants for recurrence (including life events and high family conflict ${ }^{21,28-30}$ ); (2) encourage ongoing adherence with pharmacotherapy; and (3) conduct a relapse prevention drill in which the family agreed on principles for early intervention when prodromal signs of recurrence appeared (eg, arranging an emergency psychiatric evaluation). Later phases of FFTA focused on communication enhancement training in which participants learned, through roleplaying and between-session rehearsal, skills for active listening, offering positive feedback or constructive criticism, or requesting changes in each others' behavior, and problem-solving skills training, in which participants learned to identify, generate solutions to, and implement solutions to problems in the family's day-to-day life.

Enhanced Care-Patients in EC received 3 weekly 50-minute sessions of psychoeducation with their parents and siblings. These sessions focused on relapse prevention planning, medication adherence, and keeping the home environment low in conflict. Adolescents and family members in FFT-A and EC could receive additional family or individual crisis sessions as needed throughout the 2-year study.

Therapist Training and Fidelity-All clinicians underwent standardized training on the FFT-A and EC manuals during a 2-day pretrial seminar, and then carried at least 2 cases with weekly group supervision during a treatment development trial. ${ }^{21,30}$ Therapist fidelity was tracked via audiotape review and ratings on the 13-item Therapist Competency and Adherence Scales ${ }^{31}$ that range from 1 (poor adherence) to 7 (excellent adherence). Interrater reliability (intraclass $r$ ) for the scales ranged from 0.74 to 0.98 . During the treatment development trial, mean (SD) Therapist Competency and Adherence Scale ratings for the Pittsburgh therapists were 5.0 (1.3) (good adherence, based on 20 session ratings) and for the Colorado therapists, 5.1 (0.6) (27 ratings). During the randomized trial, independent fidelity judgments of 60 FFTA or EC sessions from Colorado and Pittsburgh revealed no site differences in general therapist skills ( $P=.19$; range, 5.5-6.3), overall fidelity $(P=.29$; range, 5.0-5.9), or any other Therapist Competency and Adherence Scale $(P>.10$ for all $)$.

Assessment of Primary Outcomes-An independent evaluator interviewed the patients and at least 1 parent at study entry (covering the prior 3 months), every 3 months in year 1 , 
and every 6 months in year 2 using the Adolescent Longitudinal Interval Follow-up Evaluation $^{10,32}$ and the K-SADS DRS and MRS interviews. The evaluator, who was unaware of treatment assignments, rated each week of the prior 12 weeks (year 1) or 26 weeks (year 2) on the Adolescent Longitudinal Interval Follow-up Evaluation Psychiatric Status Rating scales (PSR) covering the severity of mania, hypomania, and major depression symptoms (ratings from 1-6). Ratings reflected a consensus between patient and parent reports. Ratings of 1 or 2 indicated asymptomatic or mildly symptomatic states; 3 or 4 , subthreshold symptoms and impairment; and 5 or 6 , fully syndromal states with varying severity and impairment.

Reliabilities for PSR ratings, established previously, were 0.74 for depressive episodes and 0.91 for manic or hypomanic episodes ( 8 patients, 53 ratings). ${ }^{10}$

Clinical status designations at study entry and follow-up were based on the presence or absence of $D S M-I V$ criteria for depression, mania, or hypomania during that 3- or 6-month interval. Recovery was assigned once all the PSR mood scales (depression and mania or hypomania) were 2 or lower for 4 or more consecutive weeks. This designation was subdivided into recovery from initial depressive symptoms (PSR depression scale $\leq 2$ for $\geq 4$ weeks) and recovery from initial mania symptoms (PSR mania or hypomania scales $\leq 2$ for $\geq 4$ weeks), which could occur at different times. Recurrence was assigned if, after a 4-week or greater period of recovery, PSR scores were 5 or greater for 1 or more weeks for mania or hypomania or 2 or more weeks for depression. We also calculated the number of weeks during the 2-year study that patients spent depressed (PSR depression score $\geq 5$ ), manic (PSR mania or hypomania score $\geq 5$ ), or well (free of significant depression or mania symptoms; PSR score $\leq 2$ ).

\section{STATISTICAL ANALYSIS}

Time to recovery from the index episode was calculated as the number of weeks from randomization until the patient met the 4-week recovery criteria above. Separate calculations were made for time to recovery from index depression symptoms and index mania symptoms. Time to recurrence was calculated as weeks from onset of recovery to onset of an acute episode (PSR scores $\geq 5$ for $\geq 1$ week for mania or hypomania or $\geq 2$ weeks for depression). Patients who did not have a recovery or recurrence or who left the study prematurely were censored at the point of their final research assessment. All randomized patients were included in the at-risk sample.

Cox proportional hazards models ${ }^{33}$ estimated the independent effect of psychosocial treatment group on time to recovery or recurrence after controlling for the effects of site, sex, initial medications, baseline illness polarity, and baseline levels of depressed or manic or hypomanic mood. Baseline mood scores were calculated as the most severe Adolescent Longitudinal Interval Follow-up Evaluation PSR score (calculated separately for depression and mania) recorded for a single week within a maximum of 5 weeks prior to randomization (for the 40 patients for whom prerandomization PSR scores were available) or a maximum of 5 weeks after randomization (for the 18 patients for whom prerandomization PSR scores were unavailable).

Our secondary hypothesis was that patients in FFT-A would spend proportionally less time in episodes and have less severe mood symptoms than patients in EC during the 2-year study.

Prior studies suggested that these treatment effects would be stronger for depression than for mania symptoms. ${ }^{17,20}$ Poisson regression models ${ }^{34}$ were used to compare the groups regarding the number of weeks in depressive episodes, number of weeks in manic or hypomanic episodes, the number of weeks well (all PSR mood scores $\leq 2$ ), weeks free of depression symptoms, and weeks free of mania or hypomania symptoms, adjusted for total weeks in the study.

Group comparisons of weekly mania and depression PSR scores were undertaken using mixedeffects regression (growth curve) models with random patient effects ${ }^{35}$ using the Proc Mixed 
application in the SAS/STAT software (SAS Institute Inc, Cary, North Carolina). ${ }^{36}$ Covariates included site, sex, baseline mood severity, baseline polarity, bipolar subtype (I, II, or NOS), and initial medication regimens. With 29 participants in each treatment arm, mixed-effects regression models had $80 \%$ power to detect a $0.75 \mathrm{SD}$ group difference in means (2-tailed $P<.05)$.

\section{RESULTS \\ STUDY SAMPLE}

Participants were 58 adolescents (33 girls [56.9\%] and 25 boys [43.1\%]; 35 [60.3\%] from Colorado, 23 [39.7\%] from Pittsburgh) with bipolar I ( $\mathrm{n}=38,65.5 \%)$, bipolar II $(\mathrm{n}=6,10.3 \%)$, or bipolar NOS disorder $(\mathrm{n}=14,24.1 \%)$ with a mean (SD) age of 14.5 (1.6) years (Table 1). The mean (SD) CGAS score for the 2 weeks prior to randomization was 57.8(11.1) (range, 35-95); for the most severe past episode, it was 44.9(12.9) (range, 35-95). Patients who began the study in depressed, manic, mixed, or subsyndromal states did not differ in current (2-week) CGAS scores $\left(F_{3,51}=1.13, P=.34\right)$, nor did patients with bipolar I, or bipolar II or NOS disorder $\left(t_{56}=0.14, P=.89\right)$.

The 58 included adolescents did not differ significantly from the 68 who were excluded (Figure $1)$ in age $(P=.08)$, sex $(P=.54)$, or racial or ethnic distribution $(P=.41)$. Exclusions were equally common at the Colorado $(45 / 80,56.3 \%)$ and Pittsburgh $(23 / 46,50.0 \%)$ sites $\left(\chi_{1}^{2}=0.46, P=\right.$. $50)$.

\section{BASELINE COMPARISONS OF TREATMENT GROUPS AND SITES}

Patients randomly assigned to FFT-A $(n=30)$ and EC $(n=28)$ did not differ in any of the demographic or illness variables listed in Table 1 . The groups did not differ at randomization on the proportion treated with 1 vs 2 mood stabilizers $(P=.12)$, atypical antipsychotics $(P=$. 38 ), or adjunctive antidepressants $(P=.09)$. There were no site differences or interactions between treatment and site on any baseline clinical, demographic, or medication variable $(P>$. 10 for all).

\section{STUDY ATTRITION AND TREATMENT COMPLETION}

As indicated in Table 2 and Figure 1, 48 of 58 (82.8\%) adolescents completed 1 year of treatment and follow-up, and 36 of $58(62.1 \%)$ completed 2 years. These proportions did not differ across the treatment groups in either year ( $P=.90$ and $P=.61$, respectively) or across the sites in either year $(P=.15$ and $P=.87$, respectively). Rates of 2-year study completion were $60 \%$ in the FFT-A group (18/30) and 64.3\% in the EC group (18/28) $(P=.73)$. Patients were followed for a mean (SD) of 83.8(31.9) weeks in FFT-A and 81.8(32.1) weeks in EC ( $P=.83)$. There were no statistically significant associations between duration of participation and sex, age, race, ethnicity, bipolar subtype, or baseline mood symptoms.

The mean (SD) number of psychotherapy sessions (including nonprotocol crisis contacts) for patients in FFT-A was 19.3(7.8) (median, 21), and in EC, 4.96(3.68) (median, 3). Patients in EC obtained a mean (SD) of 0.88 (1.86) extra family crisis sessions and 0.96(2.27) individual crisis sessions; the corresponding numbers for the FFT-A group were $0.25(0.61)$ and 0.79 (2.32), respectively. There was no difference between the sites $(P=.09)$ and no treatment $\times$ site interaction for number of psychotherapy sessions $(P=.23)$. The number of pharmacotherapy visits during the 2-year study (mean [SD], 13.4[9.4]; range, 1-48) did not differ across the FFTA and EC conditions $(P=.89)$, sites $(P=.29)$, or psychosocial conditions stratified by site $(P=$. $42)$. 


\section{PSYCHOSOCIAL TREATMENT AND RECOVERY}

Of the 58 patients, $53(91.4 \%$ ) had a full recovery from the index mood episode (all PSR mood scales $\leq 2$ for $\geq 4$ weeks) during the 2-year study. The mean (SE) time to recovery was 19.8

(3.28) weeks. Patients in FFT-A and EC did not differ in time to full recovery $\left(\chi_{1}^{2}=0.95 ; P=\right.$ 33; hazard ratio [HR], 1.33; mean [SE] FFT-A duration, 17.4 [3.74] weeks; mean [SE] EC duration, 22.3 [5.40] weeks).

The rate of recovery from index episode depression symptoms was high in both the FFT-A $(30 / 30,100.0 \%)$ and EC $(25 / 28,89.3 \%)$ conditions. However, patients in FFT-A experienced more favorable and rapid recovery from index depressive symptoms than patients in EC

$\left(\chi_{1}^{2}=4.36 ; P=.04 ; \mathrm{HR}, 1.85 ; 95 \%\right.$ confidence interval [CI], 1.04-3.29) (Figure 2). The mean (SE) time to depression recovery in FFT-A was 10.2 (2.1) weeks (25th percentile of median, 2 weeks; 95\% CI, 1-4) and in EC, 14.1 (3.34) weeks (25th percentile of median, 4 weeks; $95 \%$ CI, 3-4). There was no effect of site $(P=.81)$ and no interaction between treatment and site $(P=.55)$ regarding recovery from depressive symptoms.

There were no interactions between treatment group and baseline PSR depression scores $(P=$. $67)$ or treatment group and baseline illness polarity $(P=.83)$ for time to recovery from depression. In the subsample of 18 patients with a major depressive episode prior to randomization, the mean (SE) time to recovery from depression was 15.3 (4.47) weeks in FFTA and 22.5 (8.01) weeks in EC (HR, 4.87; 95\% CI, 1.67-14.18). Within the subgroup whose index episode was subsyndromal, the mean (SE) time to depression recovery was 5.7 (1.68) weeks in FFT and 9.2 (2.86) weeks in EC (HR, 2.18; 95\% CI, 0.75-6.27).

There was no interaction between treatment group and bipolar subtype (I vs II or NOS) in time to recovery from index depression symptoms $\left(\chi_{1}^{2}=1.60 ; P=.21\right)$. The mean (SE) time to recovery within the bipolar I subgroup ( $\mathrm{n}=38)$ was 10.6 (2.71) weeks (25th percentiles of median, 2.5; 95\% CI, 1-4) for FFT-A and 13.4 (4.08) weeks (25th percentile of median, 4; $95 \%$ CI, 1-4) for EC (HR, 1.48; 95\% CI, 0.7-3.0). For the bipolar II and NOS patients $(\mathrm{n}=20)$, the mean (SE) times to recovery were 9.4 (3.41) weeks (25th percentile of median, 2; 95\% CI, 0-6) for FFT-A and 8.1 (1.62) weeks (25th percentile of median, 4; 95\% CI, 4-7) for EC (HR, 2.83; 95\% CI, 0.9-8.5).

By 1 year, 29 of $30(96.7 \%)$ of the patients in FFT-A and 28 of 28 (100\%) of the patients in EC met the 4-week recovery criteria for mania or hypomania. The group difference in time to recovery from mania, although favoring FFT-A (mean [SE], 7.6 [1.37] weeks; for EC, 13.79

[3.54] weeks), did not reach significance $\left(\chi_{1}^{2}=2.53 ; P=.11\right.$; HR, $\left.1.58 ; 95 \% \mathrm{CI}, 0.9-2.8\right)$. There were no interactions between treatment and index polarity $(P=.48)$ or treatment and bipolar subtype $(P=.52)$ in time to recovery from mania symptoms.

\section{PSYCHOSOCIAL TREATMENT AND RECURRENCE}

Of the 53 adolescents who achieved 4 weeks of full recovery, $26(49.1 \%)$ had at least 1 recurrence in 2 years. Of these, $20(37.7 \%)$ had a recurrence of depression and $15(28.3 \%)$ had a recurrence of mania $(n=12)$ or hypomania $(n=3)$. The mean $(S E)$ time between onset of recovery and recurrence was 62.4 (7.43) weeks. There was no effect of psychosocial treatment on time to any mood disorder recurrence $\left(\chi_{1}^{2}=0.50 ; P=.48 ; \mathrm{HR}, 0.74\right)$, depression recurrence $\left(\chi_{1}^{2}=0.11 ; P=.74 ; \mathrm{HR}, 0.85\right)$ or mania or hypomania recurrence $\left(\chi_{1}^{2}=0.34 ; P=.56 ; \mathrm{HR}, 1.36\right)$.

Consistent with our hypotheses, patients in FFT-A spent less time in acute states of depression (estimate, 3.3 weeks; 95\% CI, 2.7-4.0) during the 2-year study than patients in EC (5.0 weeks; 95\% CI, 4.2-5.9; $\left.\chi_{1}^{2}=13.03 ; P<.001\right)$. Patients in FFT-A and EC did not differ in the number 
of weeks free from all mood disorder symptoms $\left(\chi_{1}^{2}=1.30 ; P=.25\right)$. Patients in FFT-A, however, spent more time (average, $70.3 \%$ of total weeks) without symptoms of depression (estimate, 52.6 weeks; 95\% CI, 50.0-55.4) than patients in EC (average, 66.3\% of total weeks; estimate, 48.3 weeks; $95 \%$ CI, 45.7-51.0; $\left.\chi_{1}^{2}=5.93 ; P=.02\right)$.

There were no interactions between treatment group and polarity of the index episode $(P=.77)$ or treatment group and bipolar subtype $(P=.68)$ in the number of depression-free weeks. Notably, patients in FFT-A who began the study in a syndromally depressed state had more depression-free weeks (mean [SD], 53.8 [27.9] weeks) at follow-up than patients in EC who began in a depressed state (mean [SD], 44.7 [35.2] weeks). Comparable effects of FFT-A were not observed for time spent in manic episodes $\left(\chi_{1}^{2}=0.01 ; P=.91\right)$ or time spent remitted from manic episodes $\left(\chi_{1}^{2}=1.99 ; P=.16\right)$.

\section{LONGITUDINAL TRAJECTORY OF MOOD SYMPTOMS}

Patients in FFT-A had greater overall reductions in mood severity scores (the worst score recorded for the mania, hypomania, or depression PSR scales for each week of follow-up) than patients in EC over 2 years $\left(F_{1,5017}=7.49, P=.006\right)$. This treatment $\times$ time interaction was independent of the main effects of baseline depression $\left(F_{1,51}=12.90, P<.001\right)$ or baseline mania or hypomania symptoms $\left(F_{1,51}=3.68, P=.06\right)$ on mood severity scores at follow-up. The treatment $\times$ time interaction was equally robust $\left(F_{1,5017}=7.58, P=.006\right)$ when baseline illness polarity was included in the model. No treatment $\times$ polarity interaction was observed $\left(F_{3,48}=1.20, P=.31\right)$. There was no main effect of site $(P=.27)$ or bipolar I vs II or NOS subtype $(P=.28)$ on the trajectory of mood symptom scores.

Decomposing the overall mood symptom score revealed that FFT-A was associated with a more favorable trajectory of PSR depression scores, even when baseline depression scores were covaried (treatment $\times$ time interaction, linear effect, $F_{1,5014}=9.23, P=.002$; quadratic effect, $F_{1,5014}=4.70, P=.03$; difference in $-2 \log$-likelihood $2=14.0, P<.001$; Figure 3$)$. The groups did not differ in the trajectory of mania or hypomania symptoms for 24 months $\left(F_{1,5044}=0.003, P=.96\right)$.

\section{EFFECTS OF MEDICATION REGIMENS}

At the 12-month follow-up, patients in FFT-A and EC did not differ in the likelihood of treatment with 1 vs 2 mood stabilizers $(P=.99)$, antipsychotics $(P=.89)$, antidepressants $(P=$. $99)$, or anxiolytics $(P=.49)$. The effects of FFT-A on speed of recovery from depression did not change when antidepressant exposure at baseline (present or absent) and initial PSR depression scores were covaried $\left(\chi_{1}^{2}=3.87 ; P=.05 ; \mathrm{HR}, 1.84\right)$. Moreover, FFT-A remained associated with more mean (SD) weeks free of depressive symptoms (52.7 [3.9]) than EC (48.2 [3.8]) $\left(\chi_{1}^{2}=5.88 ; P=.02\right)$ and fewer mean (SD) weeks in depressive states $(3.12[0.93])$ than EC (5.3[1.5]) $\left(\chi_{1}^{2}=18.48 ; P<.001\right)$ after including these covariates in Poisson models.

A mixed-effects regression model, including baseline PSR depression scores, site, bipolar I or II or NOS subtype, number of mood stabilizers per patient, atypical antipsychotics, and presence or absence of antidepressant exposure as covariates revealed a strong psychosocial group $\times$ time interaction on PSR depression scores for 2 years (linear trend, $F_{1,5014}=9.08, P=$. 003; quadratic trend, $F_{1,5014}=4.62, P=.03$; difference in -2 log-likelihood ratio test for treatment effects, $13.8 ; P<.01)$. These interactions indicate greater stabilization in the FFT-A than the EC condition. 


\section{COMMENT}

To our knowledge, this is the first randomized controlled trial of a psychosocial intervention for adolescent bipolar disorder. We examined the effectiveness of medication and FFT-A, a psychosocial intervention originally developed for adults, in 58 bipolar adolescents followed for 2 years after an illness episode. The FFT-A was administered with high levels of therapist fidelity across 2 sites. In comparison with adolescents treated with medication and 3 sessions of family psychoeducation (EC group), patients in FFT-A had shorter times to recovery from depression, less time in depressive episodes, and lower depression severity scores for 2 years. Naturalistic studies find that $70 \%$ to $100 \%$ of bipolar children and adolescents recover from acute episodes within 1 to 5 years. $5,8,10$ However, the speed and quality of recovery may be enhanced by involving the family in psychoeducational treatment.

The results are similar to those of recent trials comparing intensive psychotherapy to brief psychoeducation or routine care for bipolar adults. ${ }^{16-20,37}$ In the multisite Systematic

Treatment Enhancement Program for Bipolar Disorder study, patients (N=293) who began in a bipolar depressive episode and who received medication and up to 30 sessions of psychotherapy (FFT, interpersonal therapy, or cognitive-behavior therapy) had more rapid recoveries from depressive episodes than patients who received medication and 3 psychoeducational sessions. ${ }^{19,20}$ Much like the Systematic Treatment Enhancement Program for Bipolar Disorder, the present study found effects of FFT-A on depression symptoms, but not mania symptoms.

To enhance full symptomatic and functional recovery among adolescents, FFT-A may need to be supplemented with collaborative care interventions found effective in mania stabilization. Notably, 2 trials of systematic care management for adults with bipolar I disorder found that the combination of group psychoeducation, prodromal symptom monitoring, and systematic application of pharmacotherapy guidelines was more effective than usual care in reducing the severity and duration of manic symptoms. ${ }^{38,39}$ In contrast, the emphasis in FFT-A on reducing conflict in family relationships, enhancing social supports, and teaching interpersonal skills may underlie its stronger effects on bipolar depression. ${ }^{40,41}$

We did not examine whether the effects of family intervention on time to recovery or symptom severity translated into differences in functioning or quality of life among teens, as we had observed among bipolar adults. ${ }^{19}$ DelBello et al ${ }^{42}$ observed that $86 \%$ of bipolar adolescents recovered syndromally in the year after an acute episode, but only $41 \%$ achieved functional recovery. Future studies should consider the course of adolescent functioning, notably during the transition to adulthood, in patients treated with FFT-A or other psychosocial interventions.

The conclusions from this study are tempered by several limitations. First, there was considerable variability in the clinical status of patients at entry: $43 \%(n=25)$ had subsyndromal episodes, $31 \%(\mathrm{n}=18)$ had depressive episodes, and 12 (21\%) had manic episodes; 38 of 58 $(65.5 \%)$ had bipolar I disorder. This heterogeneity is not atypical in samples of bipolar youth. 10,12 We saw no evidence that pretreatment clinical status moderated the effects of FFT-A on symptom outcomes. However, our design was underpowered to detect treatment by baseline polarity (or treatment by bipolar subtype) interactions that, for a moderate effect size (Cohen's $d=0.5, P<.05$ ), would have required 64 patients in each of 4 cells, or 256 participants.

By design, this study did not equate the treatment conditions with number of therapy contacts. Thus, we were unable to determine whether the effects of FFT-A were due its specific content, nonspecific factors such as the therapist-patient working alliance, ${ }^{43-45}$ or simply its greater number of contact hours ( 21 hours vs 3 hours in EC) and by extension, greater opportunities for therapists to communicate changes in patients' mood states to the treating psychiatrists. Brief interventions such as EC are typically associated with only a $20 \%$ improvement rate in 
childhood mood disorders. ${ }^{10,46,47}$ Possibly, a more intensive EC treatment with the same amount of therapist contact and prodromal symptom monitoring as FFT-A, but without the additional skills training components, would have performed just as well in reducing time to recovery and episode length.

The issue of therapy specificity is particularly important in light of Goodyer and colleagues ${ }^{46}$ finding that a 9 -session nonspecific care intervention in combination with a selective serotonin reuptake inhibitor performed just as well as 19 sessions of cognitivebehavior therapy plus a selective serotonin reuptake inhibitor in stabilizing major depression among adolescents. In contrast, a randomized trial in bipolar, manic adults found that 21 sessions of FFT and medication were more effective than a time-matched, 21-session individual psychoeducational treatment and medication in preventing recurrences and rehospitalizations for 2 to 3 years. ${ }^{18}$ Comparisons of active and control treatments of identical duration and frequency, and systematic examination of treatment mediators (that in prior FFT studies have included improvements in family communication and medication adherence ${ }^{16}$, ${ }^{17}$ ) would help to disentangle the contributions of treatment content vs frequency to the outcomes of adolescents with bipolar disorder.

Although pharmacotherapy was administered by study psychiatrists who followed bestpractice guidelines, regimens could be modified at any point during the study based on clinical need. Patients in FFT-A and EC did not differ in medication regimens at the time of randomization or at the 12-month follow-up, nor did baseline regimens account for the effectiveness of FFT-A. Nonetheless, group differences in drug dosages or adherence might have emerged at any point during the 2-year follow-up. Future research should examine whether intensive psychosocial intervention in the interval following an acute episode enhances pharmacological adherence or reduces the later need for complex pharmacotherapy among pediatric bipolar patients.

\section{Acknowledgments}

Funding/Support: This study was supported by NIMH grants R21-MH62555 and R01-MH073871, a Distinguished Investigator Award from the National Alliance for Research on Schizophrenia and Depression, and a Faculty Fellowship from the University of Colorado Council on Research and Creative Work (Dr Miklowitz); and NIMH grants MH066371 (Dr Brent) and MH01878 (Dr Axelson).

\section{REFERENCES}

1. Merikangas KR, Akiskal HS, Angst J, Greenberg PE, Hirschfeld RMA, Petukhova M, Kessler RC. Lifetime and 12-month prevalence of bipolar spectrum disorder in the National Comorbidity Survey replication. Arch Gen Psychiatry 2007;64(5):543-552. [PubMed: 17485606]

2. Perlis RH, Miyahara S, Marangell LB, Wisniewski SR, Ostacher M, DelBello MP, Bowden CL, Sachs GS, Nierenberg AA, STEP-BD Investigators. Long-term implications of early onset in bipolar disorder: data from the first 1000 participants in the Systematic Treatment Enhancement Program for Bipolar Disorder (STEP-BD). Biol Psychiatry 2004;55(9):875-881. [PubMed: 15110730]

3. Brent DA, Perper JA, Goldstein CE, Kolko DJ, Allan MJ, Allman CJ, Zelenak JP. Risk factors for adolescent suicide: a comparison of adolescent suicide victims with suicidal inpatients. Arch Gen Psychiatry 1988;45(6):581-588. [PubMed: 3377645]

4. Geller B, Bolhofner K, Craney JL, Williams M, Delbello MP, Gunderson K. Psychosocial functioning in a prepubertal and early adolescent bipolar disorder phenotype. J Am Acad Child Adolesc Psychiatry 2000;39(12):1543-1548. [PubMed: 11128332]

5. Geller B, Tillman R, Craney JL, Bolhofner K. Four-year prospective outcome and natural history of mania in children with a prepubertal and early adolescent bipolar disorder phenotype. Arch Gen Psychiatry 2004;61(5):459-467. [PubMed: 15123490] 
6. Coryell W, Solomon D, Turvey C, Keller M, Leon AC, Endicott J, Schettler P, Judd L, Mueller T. The long-term course of rapid-cycling bipolar disorder. Arch Gen Psychiatry 2003;60(9):914-920. [PubMed: 12963673]

7. Schneck CD, Miklowitz DJ, Calabrese JR, Allen MH, Thomas MR, Wisniewski SR, Miyahara S, Shelton MD, Ketter TA, Goldberg JF, Bowden CL, Sachs GS. Phenomenology of rapid cycling bipolar disorder: data from the first 500 participants in the Systematic Treatment Enhancement Program for Bipolar Disorder. Am J Psychiatry 2004;161(10):1902-1908. [PubMed: 15465989]

8. Pavuluri MN, Birmaher B, Naylor MW. Pediatric bipolar disorder: a review of the past 10 years. J Am Acad Child Adolesc Psychiatry 2005;44(9):846-871. [PubMed: 16113615]

9. Axelson D, Birmaher B, Strober M, Gill MK, Valeri S, Chiappetta L, Ryan N, Leonard H, Hunt J, Iyengar S, Bridge J, Keller M. Phenomenology of children and adolescents with bipolar spectrum disorders. Arch Gen Psychiatry 2006;63(10):1139-1148. [PubMed: 17015816]

10. Birmaher B, Axelson D, Strober M, Gill MK, Valeri S, Chiappetta L, Ryan N, Leonard H, Hunt J, Iyengar S, Keller M. Clinical course of children and adolescents with bipolar spectrum disorders. Arch Gen Psychiatry 2006;63(2):175-183. [PubMed: 16461861]

11. Moreno C, Laje G, Blanco C, Jiang H, Schmidt AB, Olfson M. National trends in the outpatient diagnosis and treatment of bipolar disorder in youth. Arch Gen Psychiatry 2007;64(9):1032-1039. [PubMed: 17768268]

12. Kowatch RA, Fristad M, Birmaher B, Wagner KD, Findling RL, Hellander M, Child Psychiatric Workgroup on Bipolar Disorder. Treatment guidelines for children and adolescents with bipolar disorder. J Am Acad Child Adolesc Psychiatry 2005;44(3):213-235. [PubMed: 15725966]

13. Fristad MA, Gavazzi SM, Mackinaw-Koons B. Family psychoeducation: an adjunctive intervention for children with bipolar disorder. Biol Psychiatry 2003;53(11):1000-1009. [PubMed: 12788245]

14. West AE, Henry DB, Pavuluri MN. Maintenance model of integrated psychosocial treatment in pediatric bipolar disorder: a pilot feasibility study. J Am Acad Child Adolesc Psychiatry 2007;46(2): 205-212. [PubMed: 17242624]

15. Goldstein TR, Axelson DA, Birmaher B, Brent DA. Dialectical behavior therapy for adolescents with bipolar disorder: a 1-year open trial. J Am Acad Child Adolesc Psychiatry 2007;46(7):820-830. [PubMed: 17581446]

16. Miklowitz DJ. A review of evidence-based psychosocial interventions for bipolar disorder. J Clin Psychiatry 2006;67(suppl 11):28-33. [PubMed: 17029494]

17. Miklowitz DJ, George EL, Richards JA, Simoneau TL, Suddath RL. A randomized study of familyfocused psychoeducation and pharmacotherapy in the out-patient management of bipolar disorder. Arch Gen Psychiatry 2003;60(9):904-912. [PubMed: 12963672]

18. Rea MM, Tompson M, Miklowitz DJ, Goldstein MJ, Hwang S, Mintz J. Family focused treatment vs individual treatment for bipolar disorder: results of a randomized clinical trial. J Consult Clin Psychol 2003;71(3):482-492. [PubMed: 12795572]

19. Miklowitz DJ, Otto MW, Frank E, Reilly-Harrington NA, Kogan JN, Sachs GS, Thase ME, Calabrese JR, Marangell LB, Ostacher MJ, Patel J, Thomas MR, Araga M, Gonzalez JM, Wisniewski SR. Intensive psychosocial intervention enhances functioning in patients with bipolar depression: results from a 9-month randomized controlled trial. Am J Psychiatry 2007;164(9):1340-1347. [PubMed: 17728418]

20. Miklowitz DJ, Otto MW, Frank E, Reilly-Harrington NA, Wisniewski SR, Kogan JN, Nierenberg AA, Calabrese JR, Marangell LB, Gyulai L, Araga M, Gonzalez JM, Shirley ER, Thase ME, Sachs GS. Psychosocial treatments for bipolar depression: a 1-year randomized trial from the Systematic Treatment Enhancement Program. Arch Gen Psychiatry 2007;64(4):419-427. [PubMed: 17404119]

21. Miklowitz DJ, Biuckians A, Richards JA. Early-onset bipolar disorder: a family treatment perspective. Dev Psychopathol 2006;18(4):1247-1265. [PubMed: 17064437]

22. American Psychiatric Association. Diagnostic and Statistical Manual of Mental Disorders. Vol. 4th ed.. American Psychiatric Press; Washington, DC: 2000.

23. Chambers WJ, Puig-Antich J, Hirsch M, Paez P, Ambrosini PJ, Tabrizi MA, Davies M. The assessment of affective disorders in children and adolescents by semi-structured interview: test-retest reliability. Arch Gen Psychiatry 1985;42(7):696-702. [PubMed: 4015311] 
24. Kaufman J, Birmaher B, Brent D, Rao U, Flynn C, Moreci P, Williamson D, Ryan N. Schedule for Affective Disorders and Schizophrenia for School-Age Children-Present and Lifetime version (KSADS-PL): initial reliability and validity data. J Am Acad Child Adolesc Psychiatry 1997;36(7): 980-988. [PubMed: 9204677]

25. Axelson D, Birmaher BJ, Brent D, Wassick S, Hoover C, Bridge J, Ryan N. A preliminary study of the Kiddie Schedule for Affective Disorders and Schizophrenia for School-Age Children Mania Rating Scale for children and adolescents. J Child Adolesc Psychopharmacol 2003;13(4):463-470. [PubMed: 14977459]

26. Shaffer D, Gould MS, Brasic J, Ambrosini P, Fisher P, Bird HA. Children's Global Assessment Scale (C-GAS). Arch Gen Psychiatry 1983;40(11):1228-1231. [PubMed: 6639293]

27. Begg CB, Iglewicz B. A treatment allocation procedure for sequential clinical trials. Biometrics 1980;36(1):81-90. [PubMed: 7370375]

28. Johnson SL. Life events in bipolar disorder: towards more specific models. Clin Psychol Rev 2005;25 (8):1008-1027. [PubMed: 16129530]

29. Miklowitz DJ, Goldstein MJ, Nuechterlein KH, Snyder KS, Mintz J. Family factors and the course of bipolar affective disorder. Arch Gen Psychiatry 1988;45(3):225-231. [PubMed: 3341878]

30. Miklowitz DJ, George EL, Axelson DA, Kim EY, Birmaher B, Schneck C, Beresford C, Craighead WE, Brent DA. Family-focused treatment for adolescents with bipolar disorder. J Affect Disord 2004;82(suppl 1):S113-S128. [PubMed: 15571785]

31. Weisman AG, Okazaki S, Gregory J, Goldstein MJ, Tompson MC, Rea M, Miklowitz DJ. Evaluating therapist competency and adherence to behavioral family management with bipolar patients. Fam Process 1998;37(1):107-121. [PubMed: 9589285]

32. Keller MB, Lavori PW, Friedman B, Nielsen E, Endicott J, McDonald-Scott P, Andreasen NC. The Longitudinal Interval Follow-up Evaluation: a comprehensive method for assessing outcome in prospective longitudinal studies. Arch Gen Psychiatry 1987;44(6):540-548. [PubMed: 3579500]

33. Cox DR. Regression models and life tables. J R Stat Soc Ser B 1972;34(2):187-220.

34. Gardner W, Mulvey EP, Shaw EC. Regression analyses of counts and rates: Poisson, overdispersed Poisson, and negative binomial models. Psychol Bull 1995;118(3):392-404. [PubMed: 7501743]

35. Gueorguieva R, Krystal JH. Move over ANOVA: progress in analyzing repeated-measures data and its reflection in papers published in the Archives of General Psychiatry. Arch Gen Psychiatry 2004;61 (3):310-317. [PubMed: 14993119]

36. Ger, D.; Everitt, BS. Handbook of Statistical Analyses Using SAS. Vol. 2nd ed.. CRC Press; London, England: 2001.

37. Scott J, Paykel E, Morriss R, Bentall R, Kinderman P, Johnson T, Abbott R, Hay-hurst H. Cognitive behaviour therapy for severe and recurrent bipolar disorders: a randomised controlled trial. $\mathrm{Br} \mathrm{J}$ Psychiatry 2006;188:313-320. [PubMed: 16582056]

38. Bauer MS, McBride L, Williford WO, Glick H, Kinosian B, Altshuler L, Beresford T, Kilbourne AM, Sajatovic M, Cooperative Studies Program 430. Collaborative care for bipolar disorder part II: impact on clinical outcome, function, and costs. Psychiatr Serv 2006;57(7):937-945. [PubMed: 16816277]

39. Simon GE, Ludman EJ, Bauer MS, Unutzer J, Operskalski B. Long-term effectiveness and cost of a systematic care program for bipolar disorder. Arch Gen Psychiatry 2006;63(5):500-508. [PubMed: 16651507]

40. Kim EY, Miklowitz DJ. Expressed emotion as a predictor of outcome among bipolar patients undergoing family therapy. J Affect Disord 2004;82(3):343-352. [PubMed: 15555685]

41. Miklowitz DJ, Simoneau TL, George EL, Richards JA, Kalbag A, Sachs-Ericsson N, Suddath R. Family-focused treatment of bipolar disorder: 1-year effects of a psychoeducational program in conjunction with pharmacotherapy. Biol Psychiatry 2000;48(6):582-592. [PubMed: 11018229]

42. DelBello MP, Hanseman D, Adler CM, Fleck DE, Strakowski SM. Twelve month outcome of adolescents with bipolar disorder following first hospitalization for a manic or mixed episode. Am J Psychiatry 2007;164(4):582-590. [PubMed: 17403971]

43. Luborsky L, McLellan AT, Woody GE, O'Brien CP, Auerbach A. Therapist success and its determinants. Arch Gen Psychiatry 1985;42(6):602-611. [PubMed: 4004503] 
44. Startup M, Wilding N, Startup S. Patient treatment adherence in cognitive behaviour therapy for acute psychosis: the role of recovery style and working alliance. Behav Cogn Psychother 2006;34(2):191199.

45. Castonguay LG, Goldfried MR, Wiser S, Raue PJ, Hayes AM. Predicting the effect of cognitive therapy for depression: a study of unique and common factors. J Consult Clin Psychol 1996;64(3): 497-504. [PubMed: 8698942]

46. Goodyer I, Dubicka B, Wilkinson P, Kelvin R, Roberts C, Byford S, Breen S, Ford C, Barrett B, Leech A, Rothwell J, White L, Harrington R. Selective serotonin reuptake inhibitors (SSRIs) and routine specialist care with and without cognitive behaviour therapy in adolescents with major depression: randomised controlled trial. BMJ 2007;335(7611):142-149. [PubMed: 17556431]

47. Harrington R, Whittaker J, Shoebridge P, Campbell F. Systematic review of efficacy of cognitive behavioural therapies in childhood and adolescent depressive disorder. BMJ 1998;316(7144):15591563. [PubMed: 9596592] 


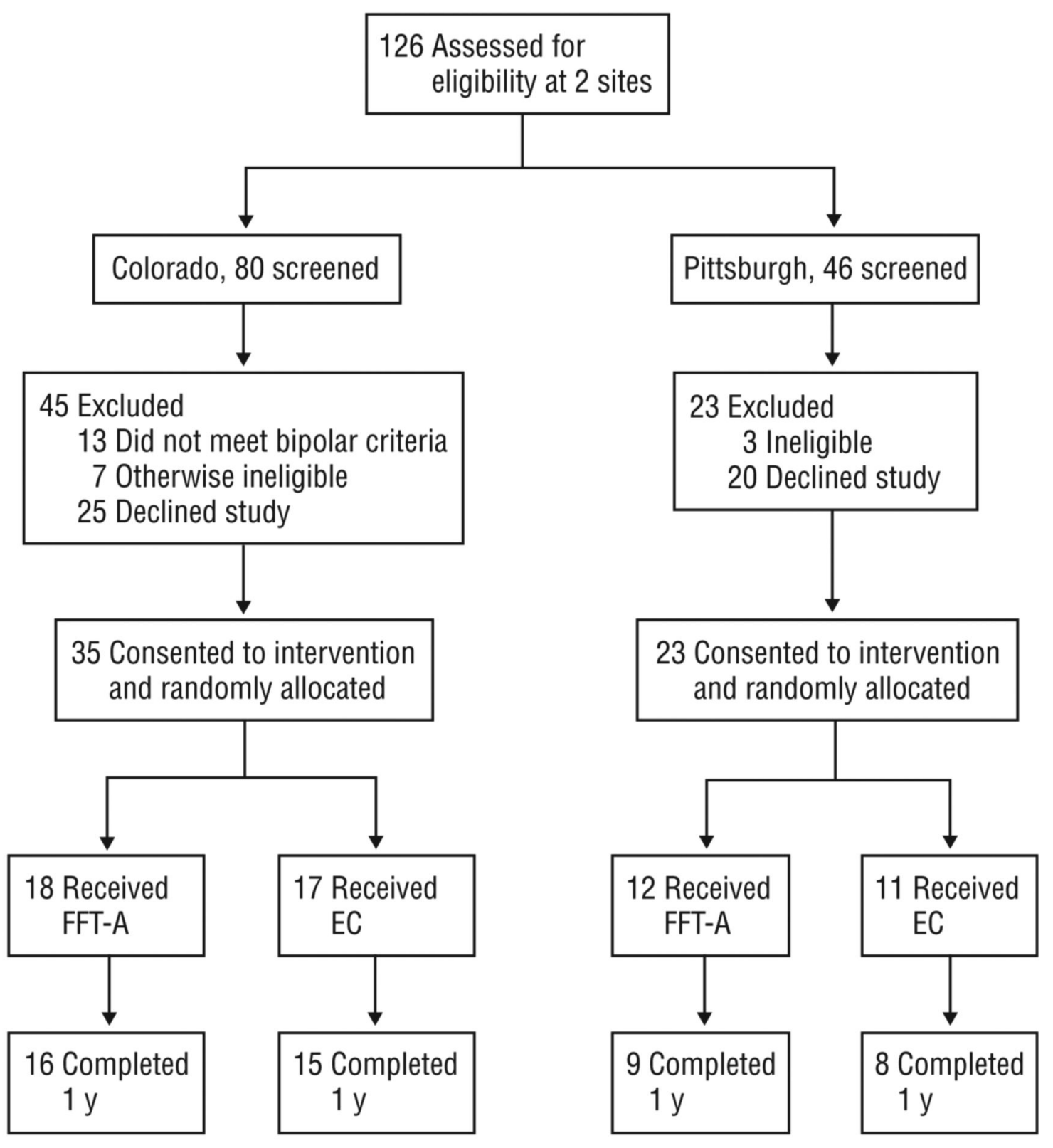

Figure 1.

CONSORT diagram. FFT-A indicates family-focused therapy for adolescents; EC, enhanced care. 


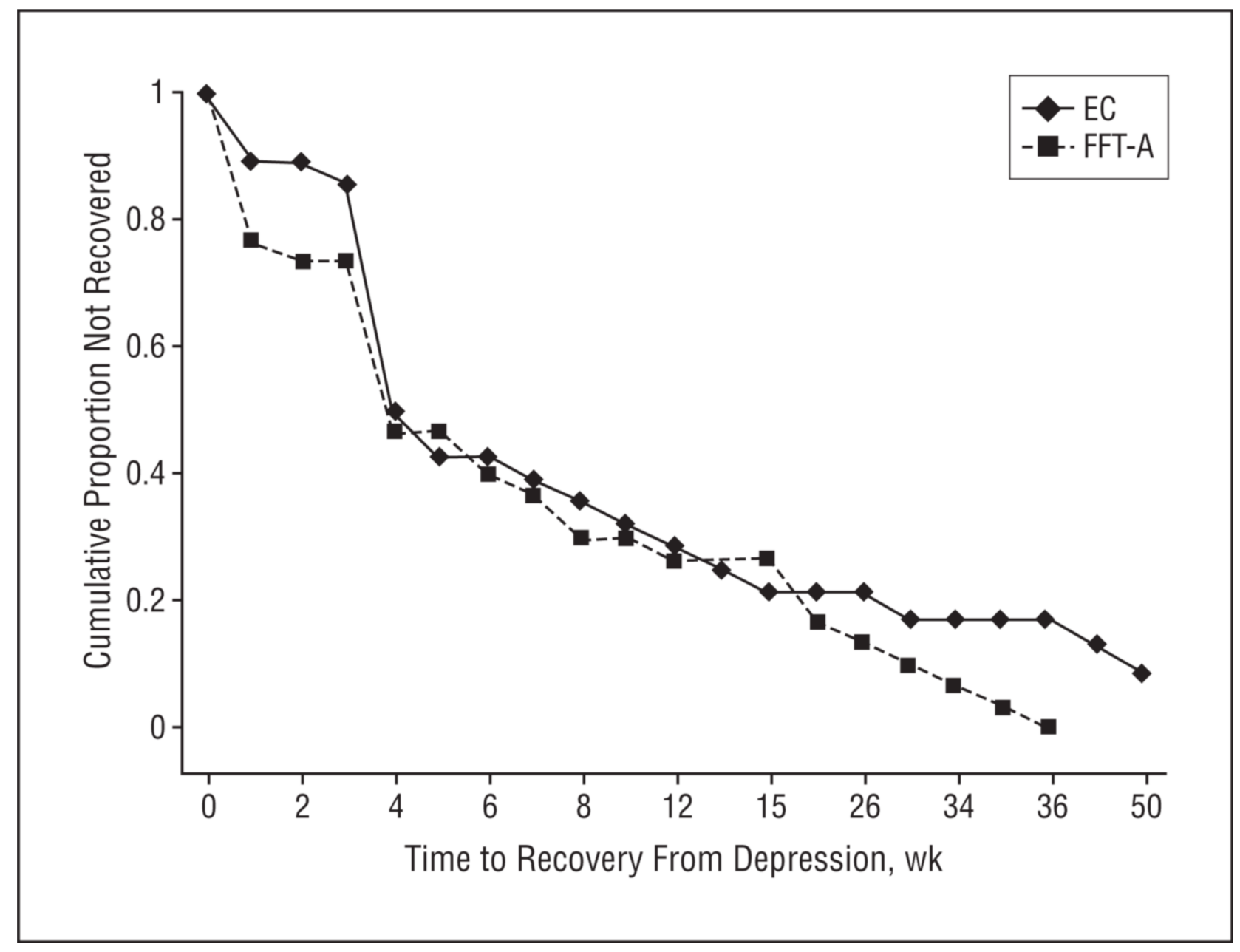

Figure 2.

Time to recovery from depressive symptoms at study intake (N=58; mean (SD), 12.4 (17.1) weeks). After accounting for baseline depression severity, site, and sex, a Cox proportional hazards model indicated that patients receiving family-focused treatment for adolescents (FFT$\mathrm{A}, \mathrm{n}=30$ ) and medication recovered from their baseline depressive symptoms faster than patients in enhanced care $(\mathrm{EC}, \mathrm{n}=28)$ and medication $\left(\chi_{1}^{2}=4.36 ; P=.04\right.$; hazard ratio, $1.85 ; 95 \%$ confidence interval, 1.04-3.29). 


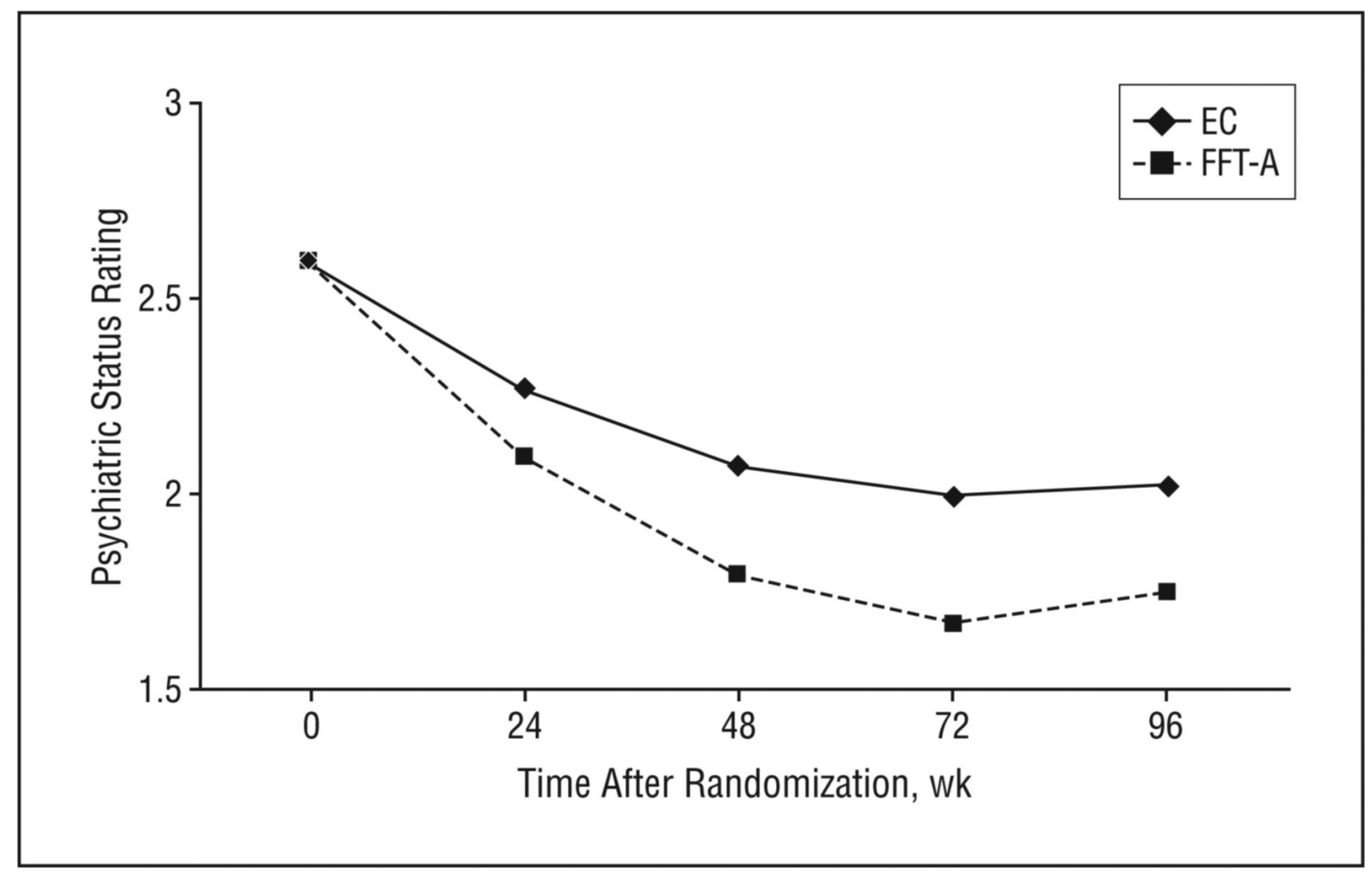

Figure 3.

Longitudinal trajectory of Psychiatric Status Ratings (PSR) from the Adolescent Longitudinal Interval Follow-up Evaluation ( $\mathrm{N}=58$ ). Family-focused treatment for adolescents (FFT-A) was associated with a more favorable trajectory of PSR depression scores than enhanced care (EC) (treatment $\times$ time interaction, linear effect, $P=.002$; quadratic effect, $P=.03$; difference in -2 log-likelihood $2=14.0, P<.001)$. 
Table 1

Demographic and Illness History Variables $(\mathrm{N}=58)$

\begin{tabular}{|c|c|}
\hline Variable $^{a}$ & Value \\
\hline \multicolumn{2}{|l|}{ Mean (SD) } \\
\hline Age, y & $14.5(1.6)$ \\
\hline K-SADS depression scale rating ${ }^{b}$ & $28.6(9.4)$ \\
\hline K-SADS mania scale rating $b$ & $24.3(9.5)$ \\
\hline \multicolumn{2}{|l|}{ CGAS rating 26} \\
\hline Current (last 2 wk) & $57.8(11.1)$ \\
\hline Most severe past episode & $44.9(12.9)$ \\
\hline Highest in prior year & $59.7(11.1)$ \\
\hline \multicolumn{2}{|l|}{ No. $(\%)$} \\
\hline \multicolumn{2}{|l|}{ Sex } \\
\hline Female & $33(56.9)$ \\
\hline \multicolumn{2}{|l|}{ Race } \\
\hline African American & $1(1.7)$ \\
\hline Native American & $1(1.7)$ \\
\hline Asian/Pacific Islander & $1(1.7)$ \\
\hline Biracial & $3(5.2)$ \\
\hline Hispanic ethnicity & $3(5.2)$ \\
\hline Live with both biological parents & $26(44.8)$ \\
\hline Bipolar I & $38(65.5)$ \\
\hline Bipolar II & $6(10.3)$ \\
\hline Bipolar not otherwise specified & $14(24.1)$ \\
\hline \multicolumn{2}{|l|}{ Index mood episode } \\
\hline Depression & $18(31.0)$ \\
\hline Mania & $12(20.7)$ \\
\hline Mixed & $3(5.2)$ \\
\hline Subthreshold ${ }^{c}$ & $25(43.1)$ \\
\hline \multicolumn{2}{|l|}{ Comorbid disorders } \\
\hline Anxiety & $2(3.5)$ \\
\hline ADHD & $11(19.0)$ \\
\hline ODD & $7(12.1)$ \\
\hline Substance abuse or dependence & $0(0.0)$ \\
\hline \multicolumn{2}{|l|}{ Medication treatments at study entry } \\
\hline 1 mood stabilizer & $35(60.0)$ \\
\hline 2 mood stabilizers & $9(15.5)$ \\
\hline 1 atypical antipsychotic & $34(58.6)$ \\
\hline 2 atypical antipsychotics & $7(12.1)$ \\
\hline Adjunctive antidepressant & $13(22.4)$ \\
\hline Adjunctive anxiolytic & $3(5.2)$ \\
\hline \multicolumn{2}{|l|}{ Type of mood stabilizer at study entry } \\
\hline Divalproex sodium & $7(12.1)$ \\
\hline
\end{tabular}

J Affect Disord. Author manuscript; available in PMC 2009 September 29. 


\begin{tabular}{lr}
\hline Variable $^{\boldsymbol{a}}$ & Value \\
\hline Lithium & $21(36.2)$ \\
Lamotrigine & $3(5.2)$ \\
Carbamazepine & $1(1.7)$ \\
Oxcarbazepine & $13(22.4)$ \\
Topiramate & $3(5.17)$ \\
Type of antipsychotic at baseline & $10(17.2)$ \\
Aripiprazole & $8(13.8)$ \\
Risperidone & $21(36.2)$ \\
Quetiapine & $4(6.9)$ \\
Olanzapine &
\end{tabular}

Abbreviations: ADHD, attention deficit hyperactivity disorder; CGAS, Children's Global Assessment Scale; K-SADS, Kiddie Schedule for Affective Disorders and Schizophrenia; ODD, oppositional defiant disorder.

${ }^{a}$ None of these variables significantly distinguished between the psychosocial treatment groups or sites, based on Mantel-Haenszel $\chi^{2}$ and 2-way analysis of variance tests.

${ }^{b}$ Refers to scores collected at entry into the study, covering the worst 1- to 2-week period in the previous 3 months.

${ }^{c}$ Adolescents with subthreshold index mood episodes had at least 1 to 2 weeks in the past 3 months with Adolescent Longitudinal Interval Follow-up Evaluation mania or depression scores $\geq 3$ and $<5$. 
Table 2

Rates of Completed Outcome Assessments Across Treatments

\begin{tabular}{ccccc}
\hline & \multicolumn{3}{c}{ No. of Patients } & \multicolumn{2}{c}{ No. (\%) } \\
\cline { 3 - 4 } Months Following Randomization & 3 & FFT-A & EC & $58(100)$ \\
& 6 & 30 & 28 & $52(89.7)$ \\
9 & 27 & 25 & 24 & $50(86.2)$ \\
12 & 26 & 23 & $48(82.8)$ \\
18 & 25 & 19 & $40(70.0)$ \\
\hline
\end{tabular}

Abbreviations: EC, enhanced care; FFT-A, family-focused treatment for adolescents. 